\title{
Assessment of the retinal vasculature in healthy Chinese preschool children aged 4-6years old using optical coherence tomography angiography
}

Lu Xiang $^{1 \dagger}$, Yingming Zhou ${ }^{1 \dagger}$, Yanwei Chen ${ }^{1}$, Siyu Jiang ${ }^{1}$, Chunli Fei ${ }^{2}$, Yangyang Wang ${ }^{2}$, Yang Bai ${ }^{2}$, Xuan Zhang ${ }^{2}$, Kai Li ${ }^{2}$ and Xi Shen ${ }^{1 *}$

\begin{abstract}
Purpose: To establish normal parameters of macular and optic disc vasculature by optical coherence tomography angiography (OCTA) in healthy preschool children aged 4-6years old in China. OCTA reflects retinal metabolism and development in children at these ages and could be used clinically and in future studies to aid diagnosis and prediction of retinal abnormalities and developmental stagnation.
\end{abstract}

Methods: In this cross-sectional study, we measured foveal, parafoveal, and perifoveal vessel density in the superficial capillary plexus (SCP); the deep capillary plexus (DCP), the foveal avascular zone (FAZ), and the radial capillary peripapillary (RPC) in the optic disc using investigational spectral-domain OCTA. The magnification effect of the FAZ area and microvasculature measurements was corrected by Littman and the modified Bennett formula.

Results: A total of 242 eyes ( 116 males and 126 females, $5.31 \pm 0.73$ years) were recruited for the analysis. The mean macular vessel density was $48.10 \pm 2.92 \%$ and $48.74 \pm 6.51 \%$ in the SCP and the DCP, respectively. The RPC vessel density was $47.17 \pm 2.52 \%, 47.99 \pm 4.48 \%$, and $48.41 \pm 3.07 \%$ in the whole image, inside disc, and peripapillary, respectively; and the mean FAZ area was $0.28 \pm 0.11 \mathrm{~mm}^{2}$. A significant difference between male and female participants was found in the retinal vasculature (DCP, SCP, and RPC). None of these parameters were significantly different in age $(P>0.05)$, except that DCP slightly increased with aging. The right and left eyes had good consistency in the parameters of the macula and optic disc.

Conclusions: Our study establishes the macular and optic disc OCTA reference values in 4- to 6-year-old healthy preschool children. They may be used in longitudinal OCTA studies and clinical applications.

Keywords: Healthy preschool children, Optical coherence tomography angiography ${ }_{2}$, Vessel density $_{3}$, Macula $_{4}$, Optic disc 5

*Correspondence: carl_shen2005@126.com

${ }^{\dagger}$ Lu Xiang and Yingming Zhou share first authorship.

${ }^{1}$ Department of Ophthalmology, Ruijin Hospital, Shanghai Jiaotong University of Medicine, Shanghai, China

Full list of author information is available at the end of the article

\section{Introduction}

The retinal vascular system supports a majority of metabolic requirements, including transporting oxygen and nourishing the retina [1]. Normal visual function relies on an intact retinal vascular system. Quantitative studies have revealed that fundamental changes in the 
microvasculature occur in the early stage of retinal [2] and optic disc diseases [3].

Over the past 50 years, fundus fluorescein angiography (FFA) and indocyanine green angiography (ICGA) have been regarded as the gold standard in diagnosing retinal [4] and choroidal diseases [5]. However, the dyeable and invasive characteristics of these procedures place limitations on frequent monitoring and repeated quantification of the vasculature, especially in children. OCT angiography (OCTA) has the inherent nature of high resolution and noninvasiveness $[6,7]$ and allows for precise and reproducible detection in both the macula [8-10] and optic disc [11, 12]. Qualitative and quantitative studies have been related to vasculature in the normal eyes [13], various retinopathies [14-16], and glaucoma [13, 17, 18] of healthy adults. Relevant factors, such as age and sex, were fully researched in these adult studies. However, explorations on the characteristics of the macular and optic disc vascular systems in healthy children are sparse. Some studies have revealed that some congenital and pediatric retinal diseases (such as familial exudative vitreoretinopathy (FEVR) $[19,20]$, retinopathy of prematurity (ROP) [21], and Coats' disease [22]) induce changes in structure and vasculature even in an asymptomatic stage. The preschool stage is a critical period for retinal and refractive development and plays a vital role in forming normal visual function [23]. Structural changes may not be recognized by clinical examination in some retinal diseases and glaucoma, but vascular changes brought to bear by OCTA could reveal the pathophysiology. Thus, it is crucial to obtain baseline OCTA data and explore the factors affecting OCTA parameters in healthy children. To date, we were unaware of previous research focusing on retinal vasculature in normal eyes of 4-6years old children worldwide. Although some studies contained these ages [24, 25], we owned a larger specimen size of this period. What's more, we corrected the magnification effect of the OCTA parameters to ensure the accuracy of our results.

Thus, our research has two aims. The first is to provide reference values of the retinal vasculature of healthy children aged 4-6years old in China. Our research will also investigate relevant factors (such as gender, age and anterior segmental parameters) to supplement the existing studies. The findings of the current study could be helpful for clinical application by detecting deviations in the retinal vasculature.

\section{Materials and Methods}

This cross-sectional study was carried out in the Wuxi Branch of Ruijin Hospital, Shanghai Jiaotong University School of Medicine. It was approved by the institutional ethics committee of Ruijin Hospital and adhered to the tenets of the Declaration of Helsinki. We obtained written informed consent from the parents or guardians before the study examination.

A total of 242 healthy Chinese subjects aged 4-6 years old were enrolled during June through November 2020 and examined by experienced optometrists. Participants completed comprehensive ocular examinations including determination of best-corrected visual acuity, slitlamp biomicroscopy, autorefraction (ARK-1a/ARK-1, Nidek, Tokyo, Japan), and non-contact intraocular pressure measurement (TX-20P, Canon, Tokyo, Japan). Axial length, anterior chamber depth, central corneal thickness, anterior chamber depth and crystalline lens thickness were obtained with optical biometry scans (Lenstar LS900, Haag-Streit AG, Koeniz, Switzerland). Atropine was instilled in both eyes three times a day for three consecutive days before data collection to facilitate cycloplegic refraction and fundoscopy. Inclusion criteria included the following: healthy subjects aged 4-6years old; no major systemic diseases or eye diseases; a BCVA of 6/12 or better; spherical equivalent between +1.0 and $+2.5 \mathrm{D}$ in 4-year-old child, between +0.5 and $+2.0 \mathrm{D}$ in 5 - and 6-year-old child, astigmatism less than $1.0 \mathrm{D}$; intraocular pressure less than $21 \mathrm{mmHg}$. Exclusion criteria included children with pathological anisometropia (spherical difference more than 1.50D), eye surgery history, amblyopia, nystagmus, retinal disease, inflammation, prematurity, neurologic disease, or systemic conditions in the ophthalmic examinations.

OCTA images were captured by RTVue Avanti spectral-domain optical coherence tomography equipped with AngioVue software (Version 2017,1,0,155; Optovue, Inc., Fremont, CA, USA) in the high-definition (HD) disc scan $(4.5 \times 4.5 \mathrm{~mm})$ and HD retina scan $(6.0 \times 6.0 \mathrm{~mm})$ modes. The images of the eye with better scan quality was chosen for further study, or if equivalent, then the eye was chosen randomly. Description of the OCTA measurements and segmentation of the retinal and vascular layers was reported in previous studies [26-30]. The magnification effect of the structural and vascular parameters in the retina was corrected using Littman and the modified Bennett formula [31]. Acquired images were eliminated when the scan quality was less than six.

We completed the statistical analysis using SPSS (SPSS for Mac, version 22.0; IBM SPSS, Inc., Chicago, IL, USA). Descriptive statistics of parameters were calculated by means, standard deviations (SD), ranges, and percentages. A one-sample Kolmogorov-Smirnov test was applied before the significance test, and all continuous variables showed normal distributions. The independent sample t-test was used to assess gender or eye-type differences, and one-way ANOVA was used to distinguish the differences between ages. Univariate and multivariate 
linear regression analyses were performed to determine the correlation between vessel density and anterior segment parameters. Simultaneously, the Spearman correlation coefficient was used to analyze the correlation between retinal thickness and vessel density in both the macula and optic disc. A $P$-value less than 0.05 was considered statistically significant.

\section{Results}

A total of 343 eyes from 343 individuals participated in our study and underwent OCTA imaging (Figs. 1 and 2). Among these, 101 eyes were excluded due to poor scan quality (with poor cooperation or significant motion artifacts). The remaining 242 eyes of 242 individuals (116 males and 126 females, mean age \pm SD $5.31 \pm 0.73$ years, range 4-6years) were recruited for quantitative assessment. None of the images needed manual correction of the automated retinal layer segmentation. The ocular parameters and demographic characteristics of the participants are listed in Tables 1 and 2.

We summarized the distributions of retinal thickness and vessel density in Tables 3 and 4 . The mean SCP was $48.10 \pm 2.92 \%$, the mean DCP was $48.74 \pm 6.51 \%$, the fovea values were lowest $(21.16 \pm 6.65 \%$ and $33.15 \pm 7.99 \%)$, the parafovea values were highest $(49.94 \pm 3.79 \%$ and $51.93 \pm 6.10 \%)$, and the values decreased outward. The mean whole image capillary of the RPC was $47.17 \pm 2.52 \%$, and the mean RNFL thickness was $96.42 \pm 10.97 \mu \mathrm{m}$. Both the RPC vessel density and RNFL thickness were highest in the inferotemporal region $(52.41 \pm 5.05 \%$ and $133.77 \pm 17.65 \mu \mathrm{m})$, followed by $51.48 \pm 4.63 \%$ and $127.48 \pm 16.11 \mu \mathrm{m}$ in the superotemporal region, respectively. The retinal vascular system of macula mainly spreads into two major plexuses: the SCP en face OCTA image was segmented with an inner boundary set at the ILM and an outer boundary at $10 \mu \mathrm{m}$ below the inner plexiform layer (ILM to IPL10), and the DCP en face OCTA image was segmented with an inner boundary $10 \mu \mathrm{m}$ below the inner plexiform layer(IPL) and an outer boundary at $10 \mu \mathrm{m}$ above the outer plexiform layer (OPL, IPL-10 to OPL +10 ). Optic disc was recorded by whole image capillary, inside-disc capillary and RPC (a $1 \mathrm{~mm}$-wide elliptical annulus extending from the optic disc boundary) in vasculature and RNFL in retinal thickness. The RPC segments extended from an inner boundary at the internal limiting membrane(ILM) to an outer boundary set at interface of nerve fiber layer (NFL).

In the evaluation of age-related parameters, a slightly significant correlation between the age of participants and DCP $(r=0.117, P=0.068$, Fig. 3) was found but not between the FAZ area, SCP, and peripapillary RPC $(P>0.05)$. Values of retinal vessel density and thickness were similar in the right and left eyes $(\mathrm{P}>0.05)$ but not in the male and female participants. The peripapillary RPC, SCP, and DCP values were significantly higher in males than in females $(P<0.001)$. In the univariate linear regression analysis, the rim area was positively correlated with the peripapillary RPC (standardized coefficients $\beta=0.195, P=0.002$ ). Axial length was positively correlated with the peripapillary RPC, SCP, and DCP (standardized coefficients $\beta=0.618, P<0.001 ; \beta=0.591$, $P<0.001 ; \beta=0.232, P<0.001)$. Other correlations in the multivariate linear regression analysis are listed in Table 5.

In the Spearman correlation analysis (Table 6), the mean SCP was correlated with peripapillary capillary RPC $(r=0.380, P<0.001$, Fig. 4). It was not significantly correlated with the mean DCP, mean SCP, or retinal thickness $(P>0.05)$. The FAZ area was similar in the left and right eyes, as well as in the male and female eyes $(P>0.05)$. It was inversely correlated with the central inner retinal thickness $(\mathrm{r}=-0.793 P<0.001$, Fig. 5) and full retinal thickness $(r=-0.737 P<0.001$, Fig. 5) and significantly negatively correlated with the foveal SCP $(r=-0.683 P<0.001$, Fig. 6$)$ and DCP $(r=-0.784$ $P<0.001$, Fig. 6).

\section{Discussion}

Various notable studies have investigated retinal thickness and vasculature in healthy adolescents [25, 27-29] and adults [26, 32-39]. This study provides new information regarding young children. We found a significant difference between male and female eyes in retinal vasculature (SCP, DCP, and RPC), with male vessel densities higher than female vessel densities. This result might be due to the serum insulin-like growth factor (IGF-1) increase in males during 4-6years old [37]. In contrast, we did not observe that age was significantly correlated with vasculature in the macular and disc areas, except that the mean DCP was slightly increased with aging; however, variable relationships were assessed in other research. Hsu et al. [25] analyzed 9-week- to 17-year-old infancies and adolescents and showed a quadratic relationship in which macular perfusion was enhanced by aging until almost 10 to 15 years old, after which it started to decrease. Qi et al. [33] investigated 1631 Chinese subjects 18-90years old and found that SCP and DCP increased with age until $60(47.53 \%)$ and $50(56.73 \%)$ years old, respectively, and then decreased. Compared to SCP and DCP in the research of Zhang et al. [27] and Coscas et al. [34], our results seemed relatively low. We inferred that the macular vasculature increased with aging in an early life stage and then decreased after the peak. Despite the fact that significant results were obtained 


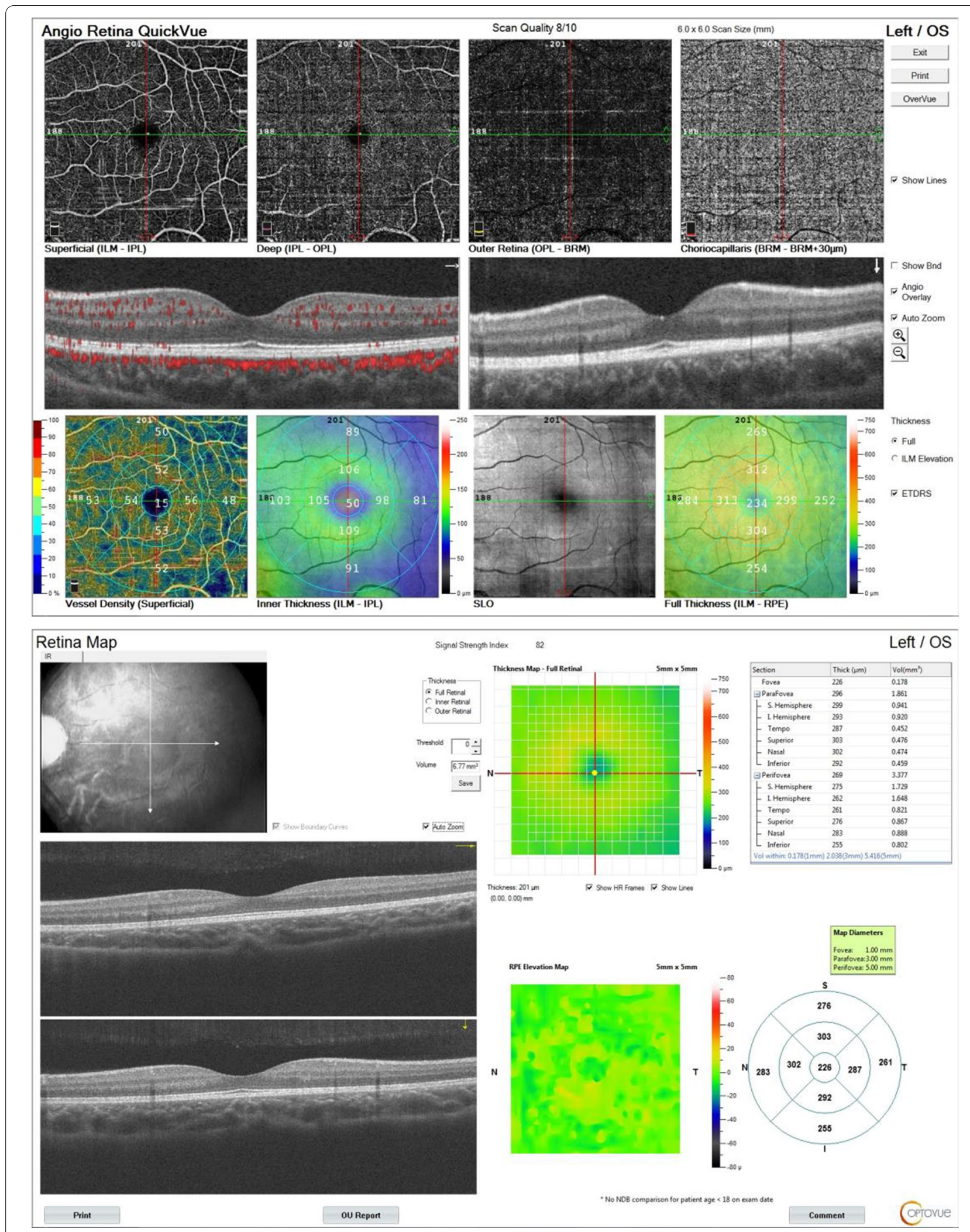

Fig. 1 Images of vascular density and retinal thickness of macular area in healthy Chinese children. The AngioVue software automatically maps and calculates the percentages occupied by vessel density in superficial and deep capillary plexus 


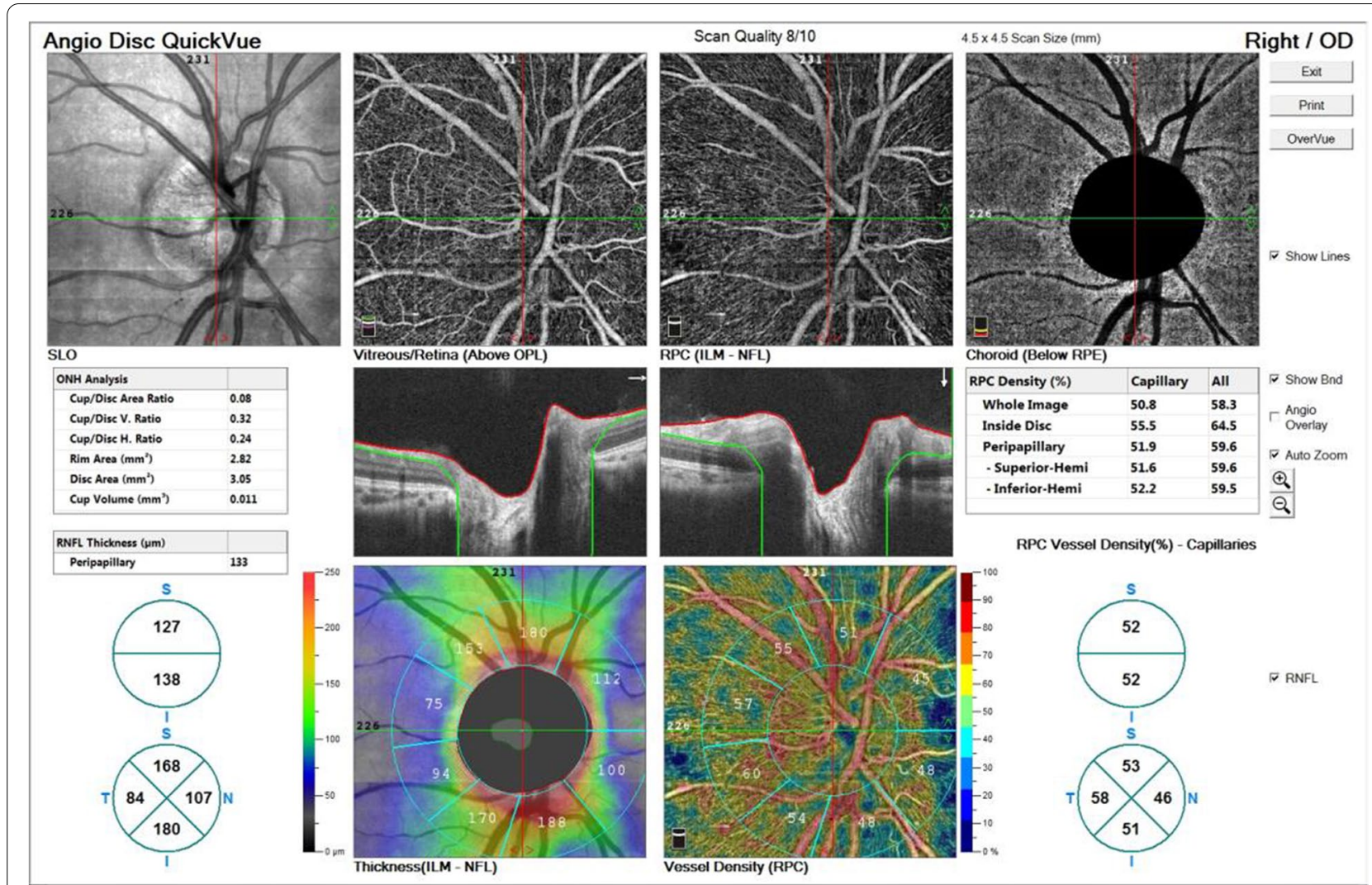

Fig. 2 Images of vascular density and retinal thickness of optic disc in healthy Chinese children. The AngioVue software automatically maps and calculates the percentages occupied by vessel density in radial peripapillary capillary

Table 1 Structural Characteristics of 4-6-year-old Chinese children

\begin{tabular}{ll}
\hline Variables & Values \\
\hline $\mathrm{IOP}(\mathrm{mmHg})$ & $15.59 \pm 2.92$ \\
$\mathrm{CCT}(\mu \mathrm{m})$ & $535.92 \pm 28.87$ \\
$\mathrm{AD}(\mathrm{mm})$ & $2.80 \pm 0.25$ \\
$\mathrm{LT}(\mathrm{mm})$ & $3.70 \pm 0.20$ \\
$\mathrm{AL}(\mathrm{mm})$ & $22.40 \pm 0.73$ \\
Disc area $\left(\mathrm{mm}^{2}\right)$ & $2.24 \pm 0.44$ \\
Cup area $\left(\mathrm{mm}^{2}\right)$ & $0.48 \pm 0.29$ \\
Rim area $\left(\mathrm{mm}^{2}\right)$ & $1.87 \pm 0.37$ \\
\hline
\end{tabular}

IOP Intraocular pressure, CCT Central corneal thickness, $A D$ Anterior chamber depth, $L T$ Lens thickness, $A L$ Axial length

Data are mean \pm standard deviation (SD)

above, we could not determine the process's definite inflection point. In the evaluation of the vasculature in the disc area, other studies performed a correlation between peripapillary RPC and age. Zhang et al. [29] noticed a stable trend in children aged 5-18 years; Jo et al. [26] recruited healthy adults $18-83$ years old and
Table 2 Demographics of preschool Chinese children stratified by age

\begin{tabular}{llll}
\hline Age $(\mathbf{y})$ & $\mathbf{4}$ & $\mathbf{5}$ & $\mathbf{6}$ \\
\hline $\mathrm{IOP}(\mathrm{mmHg})$ & $15.42 \pm 3.13$ & $16.06 \pm 2.84$ & $15.30 \pm 2.88$ \\
$\mathrm{CCT}(\mathrm{um})$ & $532.28 \pm 34.98$ & $532.82 \pm 25.95$ & $539.62 \pm 28.37$ \\
$\mathrm{AD}(\mathrm{mm})$ & $2.79 \pm 0.20$ & $2.75 \pm 0.27$ & $2.84 \pm 0.25$ \\
$\mathrm{LT}(\mathrm{mm})$ & $3.70 \pm 0.19$ & $3.72 \pm 0.18$ & $3.69 \pm 0.22$ \\
$\mathrm{AL}(\mathrm{mm})$ & $22.29 \pm 0.59$ & $22.23 \pm 0.76$ & $22.51 \pm 0.67$ \\
spherical equivalent & $2.11 \pm 0.24$ & $1.89 \pm 0.36$ & $1.71 \pm 0.37$ \\
(D) & & & \\
Scan quality & $6.90 \pm 1.07$ & $7.32 \pm 1.11$ & $7.42 \pm 1.11$ \\
\hline
\end{tabular}

IOP Intraocular pressure, CCT Central corneal thickness, $A D$ Anterior depth, $L T$ Lens thickness, AL Axial length

Data are mean \pm standard deviation (SD)

found an inverse association between age and peripapillary capillary density in almost all sectors. The relationships seemed comparable to the findings in the macula (vascular density increased with aging and then decreased with eye age). As a result, the developmental maturity of retinal vasculature in different regions is 


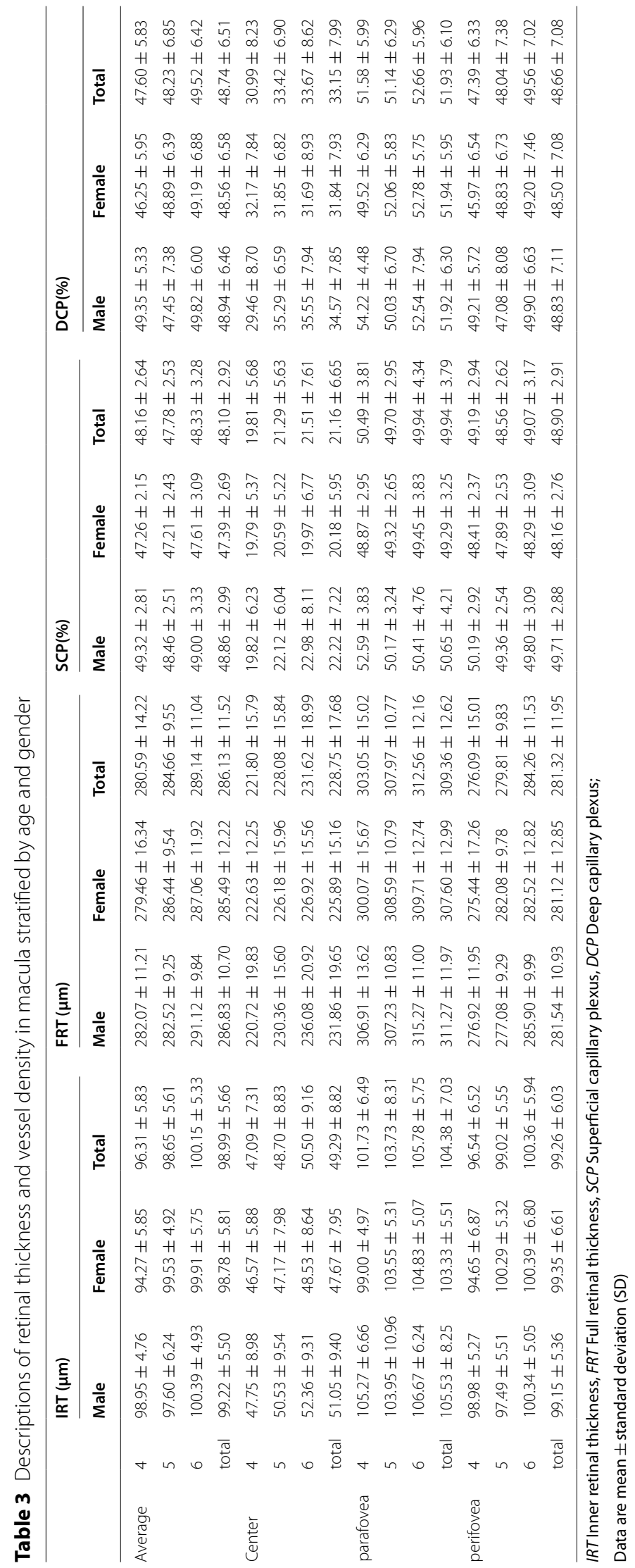


Table 4 Descriptions of retinal thickness and vessel density in optic disc stratified by age and gender

\begin{tabular}{|c|c|c|c|c|c|c|c|}
\hline & & \multicolumn{3}{|c|}{ RPC density (\%) } & \multicolumn{3}{|c|}{ RNFL thickness $(\mu \mathrm{m})$} \\
\hline & & Male & Female & Total & Male & Female & Total \\
\hline Whole- & 4 & $48.93 \pm 2.47$ & $46.68 \pm 1.53$ & $47.67 \pm 2.27$ & $99.69 \pm 14.28$ & $103.84 \pm 12.17$ & $102.03 \pm 13.12$ \\
\hline \multirow[t]{3}{*}{ image } & 5 & $47.83 \pm 2.61$ & $45.91 \pm 1.83$ & $46.79 \pm 2.40$ & $103.55 \pm 9.52$ & $104.16 \pm 11.42$ & $103.88 \pm 10.54$ \\
\hline & 6 & $47.93 \pm 2.44$ & $46.63 \pm 2.72$ & $47.29 \pm 2.65$ & $103.26 \pm 6.52$ & $105.08 \pm 13.12$ & $104.15 \pm 10.27$ \\
\hline & total & $48.05 \pm 2.51$ & $46.37 \pm 2.24$ & $47.17 \pm 2.52$ & $102.84 \pm 9.07$ & $104.52 \pm 12.25$ & $103.53 \pm 10.57$ \\
\hline Inside- & 4 & $49.21 \pm 5.27$ & $46.21 \pm 5.01$ & $47.52 \pm 5.28$ & & & \\
\hline \multirow[t]{3}{*}{ disc } & 5 & $49.13 \pm 4.14$ & $47.49 \pm 3.82$ & $48.24 \pm 4.03$ & & & \\
\hline & 6 & $47.31 \pm 5.06$ & $48.68 \pm 3.84$ & $47.98 \pm 4.54$ & & & \\
\hline & total & $48.21 \pm 4.84$ & $47.80 \pm 4.13$ & $47.99 \pm 4.48$ & & & \\
\hline \multirow[t]{4}{*}{ peripapillary } & 4 & $50.55 \pm 3.39$ & $47.88 \pm 1.96$ & $49.04 \pm 2.96$ & & & \\
\hline & 5 & $48.75 \pm 2.89$ & $46.85 \pm 2.39$ & $47.71 \pm 2.79$ & & & \\
\hline & 6 & $49.58 \pm 3.15$ & $47.83 \pm 3.11$ & $48.73 \pm 3.24$ & & & \\
\hline & total & $49.44 \pm 3.13$ & $47.46 \pm 2.70$ & $48.41 \pm 3.07$ & & & \\
\hline
\end{tabular}

Data are mean \pm standard deviation (SD)

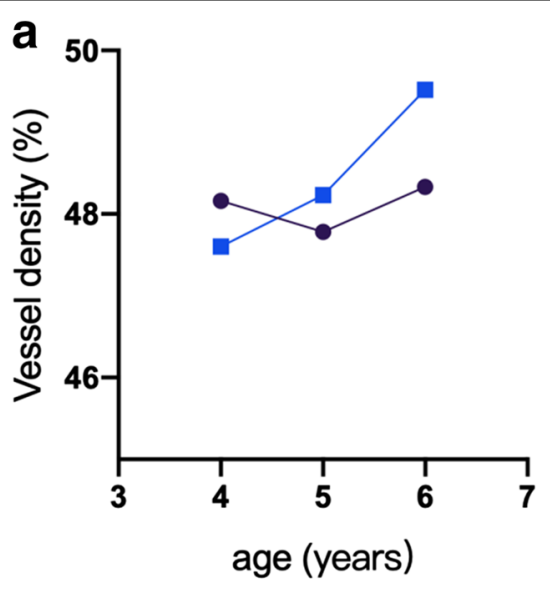

SCP whole image

DCP whole image

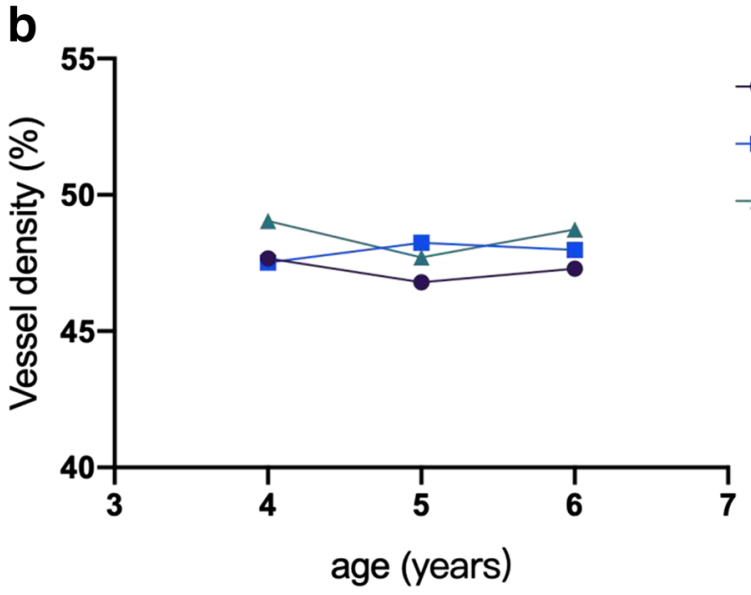

Fig. 3 Distribution of the retinal vasculature stratified by age 
Table 5 Multivariate linear regression Analysis of the retinal vasculature

\begin{tabular}{llll}
\hline & Parameters & $\begin{array}{l}\text { StandardizedCoefficients } \\
\boldsymbol{\beta}\end{array}$ & $\boldsymbol{P}$ Value \\
\hline Associations with & CCT & 0.007 & \\
mean DCP & LT & -0.001 & 0.908 \\
& AD & -0.010 & 0.994 \\
& AL & 0.225 & 0.914 \\
Associations with & CCT & -0.049 & 0.002 \\
mean SCP & LT & -0.024 & 0.440 \\
& AD & 0.136 & 0.343 \\
& AL & 0.516 & 0.711 \\
Associations with & CCT & -0.179 & 0.057 \\
peripapillary & LT & 0.060 & $<0.001$ \\
capillary & AD & -0.041 & 0.001 \\
& AL & 0.652 & 0.752 \\
& IOP & -0.049 & 0.360 \\
& & 0.560 \\
\hline
\end{tabular}

IOP Intraocular pressure, $C C T$ Central corneal thickness, $A D$ Anterior chamber depth, $L T$ Lens thickness, AL Axial length

Data are mean \pm standard deviation (SD)

accomplished at almost the same periods, which might be due to elevation of certain growth-related hormones in preschool children [40].

Regarding FAZ, its area ranges from $0.25 \mathrm{~mm}^{2}$ to $0.32 \mathrm{~mm}^{2}$ in studies that recruited more than 50 healthy subjects $[27,28,38,41-45]$, which is comparable to the current study $\left(0.30 \pm 0.13 \mathrm{~mm}^{2}\right)$. There seemed to be

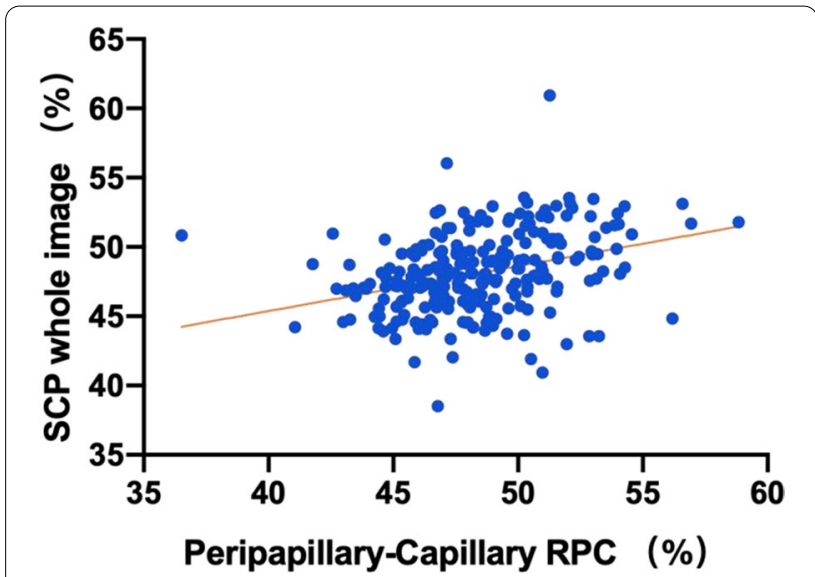

Fig. 4 Correlation between the mean SCP and peripapillary RPC

no significant relationships between age and the FAZ area in several previous studies $[25,42,45,46]$ and this one. Some researchers such as Yu et al. [38] and Pujari et al. [47] found a positive correlation across the entire life span. Consequently, according to the results from these studies [25, 27, 28, 41-47], the FAZ area does not decrease with age. It appears to be basically mature before 4-6years old and reaches a steady state or slightly decreases before complete development. Afterward, it begins to increase as eyes age.

In addition, it was recognized that the DCP was higher than the SCP in almost all macular regions in previous studies, and our results are in line with this finding $[14,27]$. Morphological features lead to vascular

Table 6 Correlation between retinal thickness and vasculature

\begin{tabular}{|c|c|c|c|c|c|c|c|c|}
\hline & & $\begin{array}{l}\text { SCP whole } \\
\text { image (\%) }\end{array}$ & $\begin{array}{l}\text { DCP whole } \\
\text { image (\%) }\end{array}$ & $\begin{array}{l}\text { Peripapillary } \\
\text { capillary RPC } \\
\text { (\%) }\end{array}$ & FAZ area $\left(\mathrm{mm}^{2}\right)$ & RNFL $(\mu \mathrm{m})$ & IRT $(\mu \mathrm{m})$ & $\mathrm{FRT}(\mu \mathrm{m})$ \\
\hline SCP whole & correlation coefficient & 1.000 & $.322^{* *}$ & $.380^{* *}$ & -.030 & -0.16 & .088 & -.005 \\
\hline image (\%) & Sig. (two-tails) & . & .000 & .000 & .642 & .807 & .174 & .940 \\
\hline DCP whole & correlation coefficient & $.322^{* *}$ & 1.000 & .078 & -.008 & .015 & -.077 & -.075 \\
\hline image (\%) & Sig. (two-tails) & .000 & & .226 & .896 & .819 & .231 & .245 \\
\hline Peripapillary & correlation coefficient & $.380^{* *}$ & .078 & 1.000 & -.113 & -.051 & -.063 & -.118 \\
\hline capillary RPC (\%) & Sig. (two-tails) & .000 & .226 & . & .080 & .425 & .327 & .066 \\
\hline FAZ area & correlation coefficient & -.030 & -.008 & -.113 & 1.000 & .060 & -.003 & -.023 \\
\hline$\left(\mathrm{mm}^{2}\right)$ & Sig. (two-tails) & .642 & .896 & .080 & . & .350 & .960 & .717 \\
\hline \multirow[t]{2}{*}{ RNFL $(\mu \mathrm{m})$} & correlation coefficient & -.016 & .015 & -.051 & .060 & 1.000 & .000 & -.027 \\
\hline & Sig. (two-tails) & .807 & .819 & .425 & .350 & . & .997 & .671 \\
\hline \multirow[t]{2}{*}{$\mathrm{IRT}(\mu \mathrm{m})$} & correlation coefficient & .088 & -.077 & -.063 & -.003 & .000 & 1.000 & $.685^{* *}$ \\
\hline & Sig. (two-tails) & .174 & .231 & .327 & .960 & .997 & . & .000 \\
\hline \multirow[t]{2}{*}{$\mathrm{FRT}(\mu \mathrm{m})$} & correlation coefficient & -.005 & -.075 & -.118 & -.023 & -.027 & $.685^{* *}$ & 1.000 \\
\hline & Sig. (two-tails) & .940 & .245 & .066 & .717 & 671 & .000 & . \\
\hline
\end{tabular}

IRT Inner retinal thickness, FRT Full retinal thickness, SCP Superficial capillary plexus, DCP Deep capillary plexus

Data are mean \pm standard deviation (SD) 


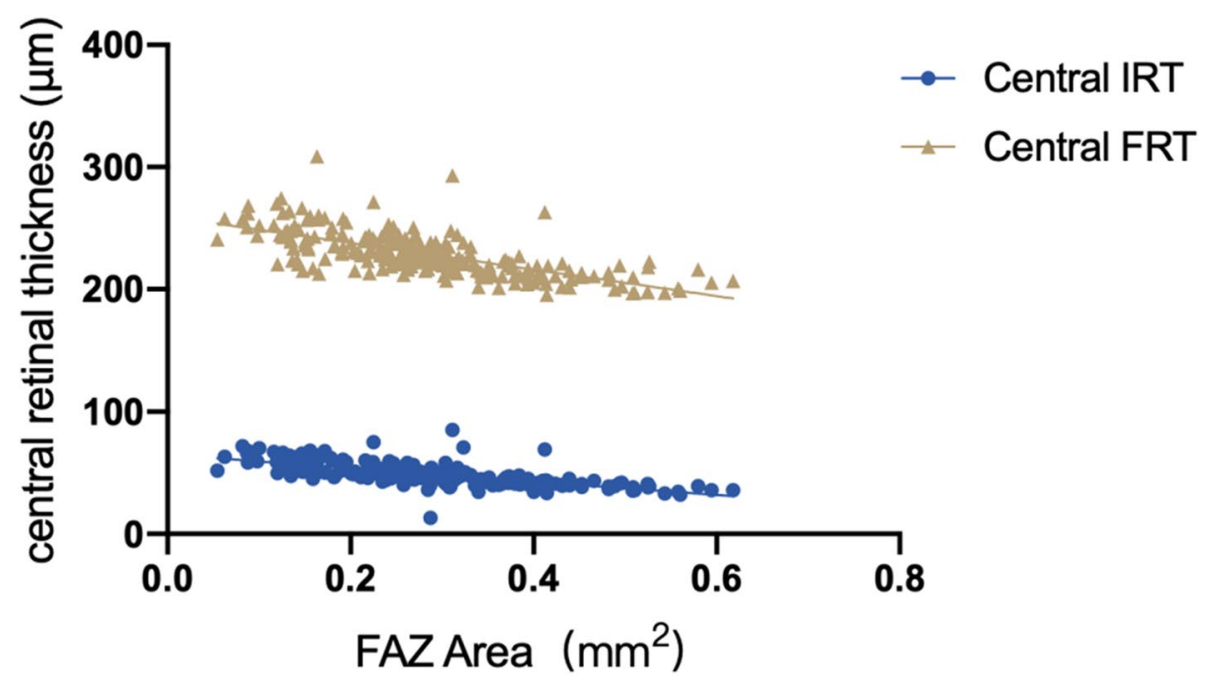

Fig. 5 Correlation between the FAZ area and central IRT and FRT

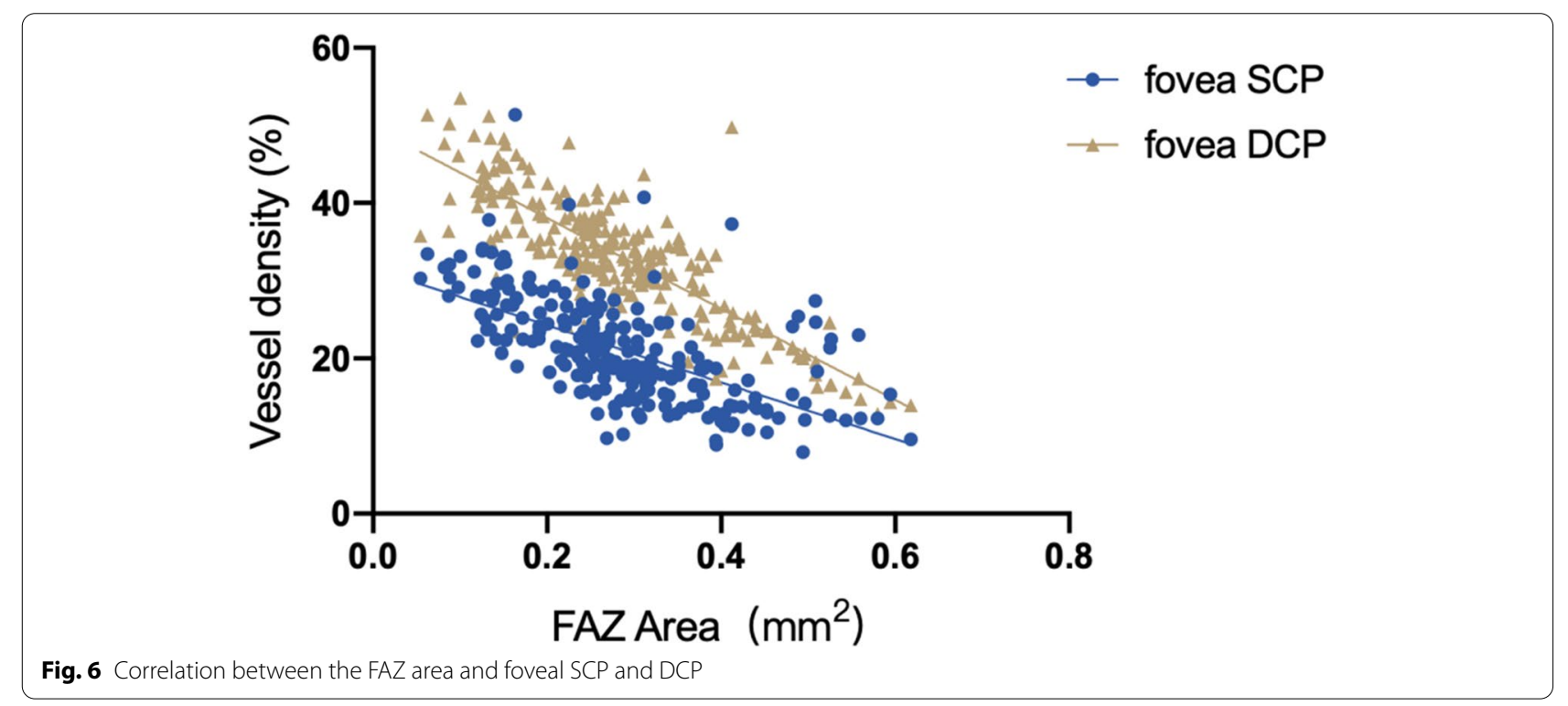

discrepancies in which the DCP consists of subtle capillary vortices and branches converging radially toward the epicenter, but linear structure capillaries form the SCP $[34,48]$. Therefore, in contrast with SCP, DCP tends to suffer a significant influence under relatively low vasculature. Kim et al. [49] found that DCP decreased preceding SCP in diabetic eyes, and circulatory disturbance occurred before structural damage. Hsu et al. [20] and Koullsis et al. [19] also revealed that DCP decreased in FEVR eyes, and macular vasculature changes could reflect peripheral vascular changes using OCTA. As a result, when the deviation of vascular values is observed, especially in DCP, it should be noted whether it is due to the abnormality in growth or damage in retinal structure.

With regard to retinal thickness and vessel density correlations and distributions, many studies have analyzed their correlations in adolescents and adults [27, 46, 50-55]. Zhang $Z$ et al. [27] found that central macular thickness was positively correlated with foveal SCP and DCP. She et al. [54] suggested that the peripapillary RPC showed a positive correlation with RNFL thickness. According to the studies above, we expected to find similar relationships in our results. However, there was no significant correlation between the macular vasculature and retinal thickness or between the RPC 
density and RNFL thickness $(P>0.05)$. Notably, the retinal vasculature is the highest metabolic network in the human body, and angioactive (angiotensin, NO), local (IOP, AL), and systemic (blood pressure, diabetes) factors regulate the circulation [38]. This might be due to the discrepancy in the factors above among children, adolescents, and adults, leading to childhood insignificance. In addition, Fujiwara et al. [46] observed that the FAZ area was inversely correlated with central retinal thickness in the inner retinal thickness and full retinal thickness and foveal vessel density in both the SCP and DCP. These findings are comparable to ours with the concept that central retinal vasculature supplies the inner retinal thickness. The interaction between the inner retinal thickness and full retinal thickness and the correlation between retinal vessel density and retinal thickness might explain the current findings. Rezar et al. [21] recently reported that the FAZ area in ROP eyes is relatively narrowed, as well as the FAZ perimeters. Araki et al. [56] found that amblyopic eyes showed a smaller FAZ area but no significant difference in the macular vasculature even after magnification error correction. Many other studies [57] in children also did not find a significant correlation in macular vasculature, but they believed that the localized defects may be specific. However, Demirayak et al. [58] showed decreased whole and parafoveal DCP and a smaller FAZ area in adult amblyopia. As FAZ area and macular vessel density were associated with poor visual acuity, we suspected that FAZ area reduction and macular vasculature defects were the initiating factors or the results of amblyopia. In the latest study, Wong et al. [59] found that the FAZ circularity and vessel density index could be sensitive markers to assess amblyopia in 30 participants with amblyopia. The large sample and multi-center studies may have more scientific guiding effect on the change of FAZ area in children with amblyopia.

Thus, an understanding of the FAZ area in children might be required in future studies. The FAZ area parameter might be used as an objective marker in the diagnosis and monitoring of abnormalities in children.

We further observed that the mean SCP was positively correlated with peripapillary RPC. Yarmohammadi et al. [60] studied the vessel densities in glaucoma and found that the vessel densities in both macular and optic discs showed a reduction, especially in the affected hemiretinae with hemifield loss. Another study showed that the peripapillary RPC was significantly higher in well-controlled primary angle-closure glaucoma (PACG) than in poorly controlled PACG [61]. We further found a positive correlation between the rim area and peripapillary RPC in the univariate and multivariate regression analyses. Iwase et al. revealed the small rim area as a new risk factor for glaucoma [62], which might be a significant sign for the development and progression of glaucoma if confirmed in the future. However, these findings were found in adults and further researches are needed on whether they could apply to children. Because retinal thickness is still growing and developing, the reduction in the RNFL may not be significant, but vascular changes, such as SCP and peripapillary RPC, may occur first. In addition, if the rim area-the high-risk factor for glaucoma-is reduced, close follow-up may be required to detect pathological changes early. Thus, the correlations must be considered when assessing and interpreting the vascular alterations in children's possible pathologic processes. Taken together, these findings warrant further investigation to acquire definite results and correlations for diagnostic applications in retinopathy and developmental stagnation of preschool children.

A longitudinal study described the emmetropization process: the rapid early progression pattern was followed by slower growth at older ages from 3 months to 6.5 years old, which led to AL elongation, AD deepening, and LT thinning [63]. We found a positive correlation between the $\mathrm{AL}$ and retinal vasculature (SCP, DCP, and RPC). Although such a relationship may occur after the magnification error is corrected, it may also be a real correlation. It shows that the anterior and posterior segments of the children's eyes develop simultaneously at this stage, although the correlation with age is not significant. However, a negative relation between the AL and retinal vasculature was found using a computer-based program to eliminate the magnification error in OCTA images [64-66]. This discrepancy might derive from the different machines, methods, and units of the retinal vessel. As these studies' small sample size could lead to result error, future studies with large samples and multiple centers are required.

Children are liable to become refractive errors, especially myopia, and experience rapid myopia progression because of sensitivity to environmental factors (e.g., heavy homework, competitive lifestyles, and few outdoor activities) in Asian countries $[67,68]$ during the emmetropization process. When an abnormality occurs, the parameter values in the anterior segment and the posterior segment will deviate from the normal value. Our normal parameter values may provide a reference for monitoring refractive development in children during this period.

Despite the strengths of our study, limitations should be noted. First, OCTA technology has inherent disadvantages of motion artifacts, superficial vascular projection, and limited scanning range. Second, the refractive development of healthy children aged 4-6years old is in the 
process of emmetropization; thus, our study was limited to hyperopia, causing a lack of the relevant retinal parameters detected in myopia. Last but not least, the narrow racial and age band limited the results' application, thus other populations need further studies.

\section{Conclusions}

In conclusion, our study demonstrated macular and optic disc reference values in 4- to 6-year-old healthy preschool children in China after magnification error was corrected by Littman and the modified Bennett formula. Overall, the density of DCP was higher than that of SCP, and the RPC density performed highest in the inferotemporal. There seemed to be an inverse correlation between the FAZ area and foveal SCP or DCP. Simultaneously, age seemed to be slightly positively related to DCP, but other vascular parameters, such as SCP and RPC vessel density, were not age-related. The current data and these relevant correlations should be considered in longitudinal OCTA studies and clinical applications.

\section{Acknowledgments}

The authors appreciate all the staff of the department of ophthalmology, the Wuxi Branch of Ruijin Hospital, Shanghai Jiaotong University School of Medicine, and families who participated in our research.

\section{Authors' contributions}

$L X, X S$, and $Y Z$ contributed to the conception of the study; $C F, Y W$, and $Y B$ performed the study; $L X, Y C, X Z$, and $K L$ contributed significantly to analysis and manuscript preparation; $L X, Y Z$, and $X S$ performed the data analyses and wrote the manuscript; YC, and SJ helped perform the analysis with constructive discussions. All authors have read and approved the manuscript. LX and YZ contributed equally as co-first authors.

\section{Funding}

No funding

\section{Availability of data and materials}

Data used by this study are available from the corresponding author upon reasonable request.

\section{Declarations}

\section{Ethics approval and consent to participate}

This cross-sectional study was carried out in the Wuxi Branch of Ruijin Hospital, Shanghai Jiaotong University School of Medicine. It was approved by the institutional ethics committee of Ruijin Hospital and adhered to the tenets of the Declaration of Helsinki. We obtained written informed consent from the parents or guardians before the study examination.

\section{Consent for publication}

Not applicable.

\section{Competing interests}

The authors declare that the research was conducted in the absence of any commercial or financial relationships that could be construed as a potential conflict of interest

\section{Author details}

'Department of Ophthalmology, Ruijin Hospital, Shanghai Jiaotong University of Medicine, Shanghai, China. ${ }^{2}$ Department of Ophthalmology, Wuxi Branch of Ruijin Hospital, Shanghai Jiaotong University of Medicine, Shanghai, China.
Received: 20 July 2021 Accepted: 22 October 2021

Published online: 02 December 2021

\section{References}

1. Yu D-Y, Cringle SJ. Oxygen distribution and consumption within the retina in vascularised and avascular retinas and in animal models of retinal disease. Prog Retin Eye Res. 2001;20(2):175-208.

2. Wylęgała A. Principles of OCTA and applications in clinical neurology. Curr Neurol Neurosci Rep. 2018;18(12):96.

3. Chan SY, Wang Q, Wang YX, Shi XH, Jonas JB, Wei WB. Polypoidal choroidal vasculopathy upon optical coherence tomographic angiography. Retina. 2018;38(6):1187-94.

4. Marmor MF, Ravin JG. Fluorescein angiography: insight and serendipity a half century Ago. Arch Ophthalmol. 2011;129(7):943-8.

5. Anantharaman G, Sheth J, Bhende M, Narayanan R, Natarajan S, Rajendran A, et al. Polypoidal choroidal vasculopathy: Pearls in diagnosis and management. Indian J Ophthalmol. 2018;66(7):896-908.

6. Rodríguez FJ, Staurenghi G, Gale R, Vision Academy Steering C. The role of OCT-A in retinal disease management. Graefes Arch Clin Exp Ophthalmol. 2018;256(11):2019-26.

7. Jia Y, Bailey ST, Hwang TS, McClintic SM, Gao SS, Pennesi ME, et al. Quantitative optical coherence tomography angiography of vascular abnormalities in the living human eye. Proc Natl Acad Sci U S A. 2015;112(18):E2395-402.

8. Ishibazawa A, Nagaoka T, Takahashi A, Omae T, Tani T, Sogawa K, et al. Optical coherence tomography angiography in diabetic retinopathy: a prospective pilot study. Am J Ophthalmol. 2015;160(1):35-44.e31.

9. Spaide RF, Klancnik JM Jr, Cooney MJ. Retinal vascular layers imaged by fluorescein angiography and optical coherence tomography angiography. JAMA Ophthalmol. 2015;133(1):45-50.

10. Eandi CM, Ciardella A, Parravano M, Missiroli F, Alovisi C, Veronese C, Morara MC, Grossi M, Virgili G, Ricci F. Indocyanine green angiography and optical coherence tomography angiography of choroidal neovascularization in age-related macular degeneration. Invest Ophthalmol Vis Sci. 2017:58(9):3690-6.

11. Singh A, Agarwal A, Mahajan S, Karkhur S, Singh R, Bansal R, et al. Morphological differences between optic disc collaterals and neovascularization on optical coherence tomography angiography. Graefes Arch Clin Exp Ophthalmol. 2017;255(4):753-9.

12. Mansoori T, Sivaswamy J, Gamalapati JS, Agraharam SG, Balakrishna N. Measurement of radial peripapillary capillary density in the normal human retina using optical coherence tomography angiography. I Glaucoma. 2017;26(3):241-6.

13. Yip VCH, Wong HT, Yong VKY, Lim BA, Hee OK, Cheng J, et al. Optical coherence tomography angiography of optic disc and macula vessel density in glaucoma and healthy eyes. J Glaucoma. 2019;28(1):80-7.

14. Lim CW, Cheng J, Tay ELT, Teo HY, Wong EPY, Yong VKY, et al. Optical coherence tomography angiography of the macula and optic nerve head: microvascular density and test-retest repeatability in normal subjects. BMC Ophthalmol. 2018;18(1):315.

15. Lévêque P-M, Zéboulon P, Brasnu E, Baudouin C, Labbé A. Optic disC vascularization in glaucoma: value of spectral-domain optical coherence tomography angiography. J Ophthalmol. 2016;2016:6956717.

16. Li L, Almansoob S, Zhang P, Zhou YD, Tan Y, Gao L. Quantitative analysis of retinal and choroid capillary ischaemia using optical coherence tomography angiography in type 2 diabetes. Acta Ophthalmol. 2019;97(3):240-6.

17. Liu L, Jia Y, Takusagawa HL, Pechauer AD, Edmunds B, Lombardi L, et al. Optical coherence tomography angiography of the peripapillary retina in glaucoma. JAMA Ophthalmol. 2015;133(9):1045-52.

18. Yarmohammadi A, Zangwill LM, Diniz-Filho A, Suh MH, Manalastas PI, Fatehee N, et al. Optical coherence tomography angiography vessel density in healthy, glaucoma suspect, and glaucoma eyes. Invest Ophthalmol Vis Sci. 2016;57(9):OCT451-9.

19. Koulisis N, Moysidis SN, Yonekawa Y, Dai YL, Burkemper B, Wood EH, et al. Correlating changes in the macular microvasculature and capillary network to peripheral vascular pathologic features in familial exudative vitreoretinopathy. Ophthalmol Retina. 2019;3(7):597-606. 
20. Hsu ST, Finn AP, Chen X, Ngo HT, House RJ, Toth CA, et al. Macular microvascular findings in familial exudative vitreoretinopathy on optical coherence tomography angiography. Ophthalmic Surg Lasers Imaging Retina. 2019;50(5):322-9.

21. Rezar-Dreindl S, Eibenberger K, Told R, Neumayer T, Steiner I, Sacu S, et al. Retinal vessel architecture in retinopathy of prematurity and healthy controls using swept-source optical coherence tomography angiography. Acta Ophthalmol. 2021;99(2):e232-9.

22. Hautz W, Gołębiewska J, Kocyła-Karczmarewicz B. Optical coherence tomography and optical coherence tomography angiography in monitoring coats' disease. J Ophthalmol. 2017;2017:7849243.

23. Talia NC, D. Virgil Alfaro I, John BK, Eric PJ. Diabetic retinopathy and angiogenesis. Curr Diabetes Rev. 2009;5(1):8-13.

24. Li S, Yang X, Li M, Sun L, Zhao X, Wang Q, et al. Developmental changes in retinal microvasculature in children: a quantitative analysis using optical coherence tomography angiography. Am J Ophthalmol. 2020;219:231-9.

25. Hsu ST, Ngo HT, Stinnett SS, Cheung NL, House RJ, Kelly MP, et al. Assessment of macular microvasculature in healthy eyes of infants and children using OCT angiography. Ophthalmology. 2019;126(12):1703-11.

26. Jo YH, Sung KR, Shin JW. Effects of age on peripapillary and macular vessel density determined using optical coherence tomography angiography in healthy eyes. Investig Opthalmol Visual Sci. 2019;60(10):3492-8.

27. Zhang Z, Huang X, Meng X, Chen T, Gu Y, Wu Y, et al. In vivo assessment of macula in eyes of healthy children 8 to 16 years old using optical coherence tomography angiography. Sci Rep. 2017;7(1):8936.

28. Borrelli E, Lonngi M, Balasubramanian S, Tepelus TC, Baghdasaryan E, lafe NA, Pineles SL, Velez FG, Sarraf D, Sadda SR, et al. Macular microvascular networks in healthy pediatric subjects. Retina. 2019;39(6):1216-24.

29. Zhang Y, Zhang B, Fan M, Gao X, Wen X, Li Z, et al. The vascular densities of the macula and optic disc in normal eyes from children by optical coherence tomography angiography. Graefes Arch Clin Exp Ophthalmol. 2020;258(2):437-44.

30. Hsiao C-C, Hsu H-M, Yang C-M, Yang C-H. Correlation of retinal vascular perfusion density with dark adaptation in diabetic retinopathy. Graefes Arch Clin Exp Ophthalmol. 2019;257(7):1401-10.

31. Sampson DM, Gong P, An D, Menghini M, Hansen A, Mackey DA, et al. Axial length variation impacts on superficial retinal vessel density and foveal avascular zone area measurements using optical coherence tomography angiography. Invest Ophthalmol Vis Sci. 2017;58(7):3065-72.

32. Girkin CA, McGwin G, Sinai MJ, Sekhar GC, Fingeret M, Wollstein G, et al. Variation in optic nerve and macular structure with age and race with spectral-domain optical coherence tomography. Ophthalmology. 2011;118(12):2403-8.

33. You QS, Chan JCH, Ng ALK, Choy BKN, Shih KC, Cheung JJC, et al. Macular vessel density measured with optical coherence tomography angiography and its associations in a large population-based study. Invest Ophthalmol Vis Sci. 2019;60(14):4830-7.

34. Coscas F, Sellam A, Glacet-Bernard A, Jung C, Goudot M, Miere A, Souied EH. Normative data for vascular density in superficial and deep capillary plexuses of healthy adults assessed by optical coherence tomography angiography. Investig Opthalmol Visual Sci. 2016;57(9):211-23.

35. Lupidi M, Coscas F, Cagini C, Fiore T, Spaccini E, Fruttini D, et al. Automated quantitative analysis of retinal microvasculature in normal eyes on optical coherence tomography angiography. Am J Ophthalmol. 2016;169:9-23.

36. Rao HL, Pradhan ZS, Weinreb RN, Reddy HB, Riyazuddin M, Sachdeva S, et al. Determinants of peripapillary and macular vessel densities measured by optical coherence tomography angiography in normal eyes. J Glaucoma. 2017;26(5):491-7.

37. lafe NA, Phasukkijwatana N, Chen X, Sarraf D. Retinal capillary density and foveal avascular zone area are age-dependent: quantitative analysis using optical coherence tomography angiography. Invest Ophthalmol Vis Sci. 2016;57(13):5780-7

38. Yu J, Jiang C, Wang $X$, Zhu L, Gu R, Xu H, et al. Macular perfusion in healthy Chinese: an optical coherence tomography angiogram study. Invest Ophthalmol Vis Sci. 2015;56(5):3212-7.

39. Yu J, Gu R, Zong Y, Xu H, Wang X, Sun X, et al. Relationship between retinal perfusion and retinal thickness in healthy subjects: an optical coherence tomography angiography study. Invest Ophthalmol Vis Sci. 2016;57(9):OCT204-10.
40. Yüce Ö, Yalçın NG, Bideci A, Döğer E, Emeksiz HC, Hasanreisoğlu M, et al. Retinal neural and vascular structure in isolated growth hormone deficiency children and evaluation of growth hormone treatment effect. J Clin Res Pediatr Endocrinol. 2018;10(2):113-8.

41. Shahlaee A, Pefkianaki M, Hsu J, Ho AC. Measurement of foveal avascular zone dimensions and its reliability in healthy eyes using optical coherence tomography angiography. Am J Ophthalmol. 2016;161:50-5 e51.

42. Zhou Y, Zhou M, Gao M, Liu H, Sun X. Factors affecting the foveal avascular zone area in healthy eyes among young chinese adults. Biomed Res Int. 2020;2020:7361492.

43. Takase N, Nozaki M, Kato A, Ozeki H, Yoshida M, Ogura Y. Enlargement of foveal avascular zone in diabetic eyes evaluated by en face optical coherence tomography angiography. Retina. 2015;35(11):2377-83.

44. de Carlo TE, Chin AT, Bonini Filho MA, Adhi M, Branchini L, Salz DA, Baumal CR, Crawford C, Reichel E, Witkin AJ, et al. Detection of microvascular changes in eyes of patients with diabetes but not clinical diabetic retinopathy using optical coherence tomography angiography. Retina. 2015:35(11):2364-70.

45. Samara WA, Say EAT, Khoo CTL, Higgins TP, Magrath G, Ferenczy S, Shields $\mathrm{CL}$. Correlation of foveal avascular zone size with foveal morphology in normal eyes using optical coherence tomography angiography. Retina. 2015;35(11):2188-95

46. Fujiwara A, Morizane Y, Hosokawa M, Kimura S, Shiode Y, Hirano M, et al. Factors affecting foveal avascular zone in healthy eyes: An examination using swept-source optical coherence tomography angiography. PLoS One. 2017;12(11):e0188572.

47. Pujari A, Chawla R, Markan A, Shah P, Kumar S, Hasan N, et al. Agerelated changes in macular vessels and their perfusion densities on optical coherence tomography angiography. Indian J Ophthalmol. 2020;68(3):494-9.

48. Savastano MC, Lumbroso B, Rispoli M. In vivo characterization of retinal vascularization morphology using optical coherence tomography angiography. Retina. 2015;35(11):2196-203.

49. Kim M, Choi SY, Park YH. Quantitative analysis of retinal and choroidal microvascular changes in patients with diabetes. Sci Rep. 2018;8(1):12146.

50. Cheung CY, Li J, Yuan N, Lau GYL, Chan AYF, Lam A, et al. Quantitative retinal microvasculature in children using swept-source optical coherence tomography: the Hong Kong children eye study. Br J Ophthalmol. 2019;103(5):672.

51. Falavarjani KG, Shenazandi H, Naseri D, Anvari P, Kazemi P, Aghamohammadi F, et al. Foveal avascular zone and vessel density in healthy subjects: an optical coherence tomography angiography study. J Ophthalmic Vis Res. 2018;13(3):260-5

52. Uzun S, Pehlivan E. Vascular density in retina and choriocapillaris as measured by optical coherence tomography angiography. Am J Ophthalmol. 2016;169:290.

53. Falavarjani KG, Shenazandi $H$, Naseri D, Anvari P, Sedaghat A, Hashemi M, et al. Correlation of optic disc morphometry and optic disc microvasculature assessed with optical coherence tomography angiography. Can J Ophthalmol. 2018;53(6):595-9.

54. She X, Guo J, Liu X, Zhu H, Li T, Zhou M, et al. Reliability of vessel density measurements in the peripapillary retina and correlation with retinal nerve fiber layer thickness in healthy subjects using optical coherence tomography angiography. Ophthalmologica. 2018;240(4):183-90.

55. Yu PK, Cringle SJ, Yu D-Y. Correlation between the radial peripapillary capillaries and the retinal nerve fibre layer in the normal human retina. Exp Eye Res. 2014;129:83-92.

56. Araki S, Miki A, Goto K, Yamashita T, Yoneda T, Haruishi K, et al. Foveal avascular zone and macular vessel density after correction for magnification error in unilateral amblyopia using optical coherence tomography angiography. BMC Ophthalmol. 2019;19(1):171.

57. Cinar E, Yuce B, Aslan F, Erbakan G. Comparison of retinal vascular structure in eyes with and without amblyopia by optical coherence tomography angiography. J Pediatr Ophthalmol: Strabismus. 2020;57(1):48-53.

58. Demirayak B, Vural A, Sonbahar O, Ergun O, Onur IU, Akarsu Acar OP, et al. Analysis of macular vessel density and foveal avascular zone in adults with amblyopia. Curr Eye Res. 2019;44(12):1381-5.

59. Wong ES, Zhang X-J, Yuan N, Li J, Pang CP, Chen L, et al. Association of optical coherence tomography angiography metrics with detection of impaired macular microvasculature and decreased vision in 
amblyopic eyes: the Hong Kong children eye study. JAMA Ophthalmol. 2020;138(8):858-65.

60. Yarmohammadi A, Zangwill LM, Diniz-Filho A, Saunders $L$, Suh MH, Wu Z, et al. Peripapillary and macular vessel density in patients with glaucoma and single-hemifield visual field defect. Ophthalmology. 2017;124(5):709-19.

61. Zhu L, Zong Y, Yu J, Jiang C, He Y, Jia Y, et al. Reduced retinal vessel density in primary angle closure glaucoma: a quantitative study using optical coherence tomography angiography. J Glaucoma. 2018;27(4):322-7.

62. Iwase A, Sawaguchi S, Tanaka K, Tsutsumi T, Araie M. Relationship between ocular risk factors for glaucoma and optic disc rim in normal eyes. Br J Ophthalmol. 2020;104(8):1120.

63. Mutti DO, Sinnott LT, Lynn Mitchell G, Jordan LA, Friedman NE, Frane SL, et al. Ocular component development during infancy and early childhood. Optom Vis Sci. 2018;95(11):976-85.

64. Li H, Mitchell P, Liew G, Rochtchina E, Kifley A, Wong TY, et al. Lens opacity and refractive influences on the measurement of retinal vascular fractal dimension. Acta Ophthalmol. 2010;88(6):e234-40.

65. Patton N, Maini R, MacGillivary T, Aslam TM, Deary IJ, Dhillon B. Effect of Axial Length on Retinal Vascular Network Geometry. Am J Ophthalmol. 2005;140(4):648.e641-7.

66. Lim LS, Cheung CY-L, Lin X, Mitchell P, Wong TY, Mei-Saw S. Influence of refractive error and axial length on retinal vessel geometric characteristics. Invest Ophthalmol Vis Sci. 2011;52(2):669-78.

67. Li T, Zhou X, Chen X, Qi H, Gao Q. Refractive error in chinese preschool children: the Shanghai study. Eye Contact Lens. 2019;45(3):182-7.

68. Ramamurthy D, Lin Chua SY, Saw SM. A review of environmental risk factors for myopia during early life, childhood and adolescence. Clin Exp Optom. 2015:98(6):497-506.

\section{Publisher's Note}

Springer Nature remains neutral with regard to jurisdictional claims in published maps and institutional affiliations.

Ready to submit your research? Choose BMC and benefit from:

- fast, convenient online submission

- thorough peer review by experienced researchers in your field

- rapid publication on acceptance

- support for research data, including large and complex data types

- gold Open Access which fosters wider collaboration and increased citations

- maximum visibility for your research: over $100 \mathrm{M}$ website views per year

At BMC, research is always in progress.

Learn more biomedcentral.com/submissions 